\title{
Progress on Off-Site Cleanup Efforts in Fukushima 2016
}

Fukushima Office for Environmental Restoration, Ministry of the Environment, Seiji Ozawa

Decontamination has been pursued in Hamadoori, Nakadoori, and various other parts of Fukushima Prefecture since the nuclear accident that occurred there in March 2011. Pursuant to the Act on Special Measures Concerning the Handling of Environmental Pollution by Radioactive Materials Discharged by the Nuclear Power Station Accident Associated with the Tohoku District - Off the Pacific Ocean Earthquake That Occurred on 11 March 2011 enacted in August of that year, the Ministry of the Environment (MOE) is conducting decontamination in 11 municipalities located in the evacuation zones. The efforts being led directly by the Japanese government are aimed at completing the extensive decontamination of the target municipalities by the end of FY2016, except in difficult-to-return zones. This article reports on the progress that has been made since the publication of the last commentary in spring 2014 as well as the challenges ahead.

KEYWORDS: Off-site cleanup, decontamination, radioactive pollution, Fukushima, Ministry of the Environment

\section{Introduction}

"Did you drink the local water and eat the local rice?" "Is decontamination really effective?" "Have you really not been affected by the radiation?" These are some of the questions that local leaders, doctors, educators, and other stakeholders often expect children from Fukushima to encounter when they grow up to become students and professionals and meet people in Sendai, Tokyo, Osaka, and other places outside Fukushima Prefecture. They believe that these children need special educational support to help them answer these questions about radiation and the situation in Fukushima. As a first step toward providing such support, this report presents information on the effectiveness of decontamination. It then provides an overview of the progress that has been made in terms of decontamination work and other cleanup efforts before discussing how to address future challenges, such as how to handle difficult-to-return zones.

DOI : 10.15669/fukushimainsights.Vol.2.116

(C) 2021 Atomic Energy Society of Japan. All rights reserved.

Originally published in Journal of the Atomic Energy Society of Japan (ISSN 1882-2606), Vol. 59, No. 1, p. 33-36 (2017) in

Japanese. (Japanese version accepted: September 30, 2016) 


\section{Effectiveness of Decontamination}

Both in the immediate aftermath of the nuclear accident and during the five year that have followed, affected residents have often questioned the effectiveness of decontamination. In briefing sessions on decontamination work and other measures, they ask if the radioactive materials produced by the accident are carried back to decontaminated areas from areas that have yet to be decontaminated or other such sources via natural phenomena such as the wind and streams. This section describes dose surveys that have been conducted along with the decontamination work, discusses their effectiveness in helping to reduce the air dose, and explains how temporary storage yards are managed, which is a matter of concern for local residents.

\section{Dose Surveys Conducted Along with the Decontamination Work}

In decontamination target areas, the air dose is surveyed in advance with due consent from the relevant landowners. Dose measurements are also conducted immediately after decontamination work has been completed. A monitoring survey is conducted about six months to one year later. If the reduced air dose is not maintained at any of the sites, the cause is investigated. If necessary, follow-up spot decontamination work is conducted, after which the relevant sites are continuously monitored.

As of August 2016, the air dose had been measured at 990,000 sites (where approximately 620,000 were in residential areas, 120,000 were on farmland, 60,000 were in forests, and 190,000 were on roads) prior to the start of the decontamination work conducted directly by the Japanese government. In areas with a relatively high dose, the radioactivity concentration is also measured in advance of any decontamination work in consultation with the local community.

The compiled findings from monitoring surveys have facilitated the identification of land features and building structures that may attract radioactive materials after their decontamination. Particular attention is paid to examining places such as the areas under gutters, cracks in asphalt and other ground surfaces, and water channels on the slopes of hills behind houses. At present, these sites are carefully examined even during the first round of decontamination work.

\section{Long-Term Monitoring Data}

Survey data is available on reductions in the air dose following decontamination work. Such data has been accumulated over the long term in the air dose rate follow-up surveys conducted in the target areas for the pilot demonstration project that was conducted by the Cabinet Office from November 2011 to April 2012.

The pilot demonstration was conducted in 18 areas located mainly in evacuation zones, and follow-up surveys have been conducted in 14 areas ${ }^{\mathrm{i}}$. Each target area has about 20 measurement sites. By the end of 2015, 11 rounds of follow-up surveys had been conducted. So far, the air dose has decreased at all of the 288 measurement sites, with different dose levels recorded throughout the area from the Ottozawa District in Okuma (average air dose rate before decontamination: $67 \mu \mathrm{Sv} / \mathrm{h}$ ) to the southern industrial complex in Naraha (average rate: $0.39 \mu \mathrm{Sv} / \mathrm{h}$ ). Continuous increases were not noted at any of the measurement sites. In these

\footnotetext{
${ }^{i}$ An additional follow-up survey was later begun in another area, resulting in the current total of 15 target areas.
} 
14 areas, the decontamination work reduced the dose by about $60 \%$ on average, with physical decay assumed to account for $50 \%$ of this reduction.

\section{Management of Temporary Storage Yards}

As of August 2016, about 270 temporary storage yards located in the evacuation zones (including zones where the evacuation order has been lifted) stored about 7 million bags of soil $\left(1 \mathrm{~m}^{3}\right.$ per bag) produced by the decontamination work conducted directly by the MOE. In addition, about 700,000 bags of combustible waste were carried away for treatment at temporary incineration facilities or the like.

Each temporary storage yard is developed in the following manner to ensure that the removed soil is managed safely until its subsequent transportation to interim storage facilities.

- An impermeable lining sheet is laid at the site.

- Large bags of the removed soil are piled up on top of the lining sheet.

- Bags of uncontaminated sand (about $1 \mathrm{~m}^{3}$ per bag) are placed around and on top of the heap to provide radiation shielding.

- The entire heap of bags, including the top, is covered with a waterproof sheet or a suitable alternative.

- This arrangement reduces the radioactivity emitted from the removed soil by over $99.8 \%$.

- The dose levels near temporary storage yards do not differ from those in the surrounding environment.

- Once a temporary storage yard has been developed, it is monitored through the following measures: regular patrols; weekly measurements of the air dose, temperature, and CO concentration; monthly measurements of the groundwater and seeping water; and quarterly mowing.

As of June 2016, about 5.5 million $\mathrm{m}^{3}$ of the soil removed in decontamination work that was not carried out directly by the Japanese government was being managed by municipal governments at their 830 temporary storage yards and 145,000 direct storage sites in Fukushima Prefecture.

\section{Aiming for the Completion of Decontamination}

\section{Special Decontamination Areas}

In special decontamination areas where the Japanese government conducts decontamination work directly, 7 of the 11 target municipalities (i.e., Tamura, Kawauchi, Naraha, Katsurao, Kawamata, Okuma, and Futaba) completed extensive decontamination work in accordance with their decontamination plans. Table 1 shows the progress that had been made by August 2016 in the remaining 4 municipalities. All of these municipalities plan to complete extensive decontamination work by the end of FY2016 according to their plans. For the decontamination work conducted in the special decontamination areas, a cumulative total of about 9 million workers were mobilized from July 2012 to August 2016. In November 2015, the largest number of workers employed on a single day reached around 20,000.

With reference to the 4 municipalities listed in Table 1, the evacuation order was lifted in Minamisoma, with the exception of difficult-to-return zones, in July 2016. In Iitate, the order is to be lifted in March 2017 (excluding difficult-to-return zones). The evacuation order has been lifted in 4 of the 7 municipalities (Tamura, Naraha, Kawauchi, and Katsurao) that have 
Table 1 Progress made in decontamination work in special decontamination areas

\begin{tabular}{|c|c|c|c|c|c|}
\hline & \multirow{2}{*}{$\begin{array}{c}\text { Consent from } \\
\text { landowners (\%) }\end{array}$} & \multicolumn{4}{|c|}{ Progress (\%) } \\
\cline { 3 - 6 } & & Residential areas & Farmland & Forests & Roads \\
\hline Iitate & 99.6 & 100 & 91 & 98 & 82 \\
\hline Minamisoma & 95 & 96 & 38 & 69 & 39 \\
\hline Namie & 98 & 87 & 51 & 96 & 75 \\
\hline Tomioka & Completed & 100 & 99 & 100 & 99.9 \\
\hline
\end{tabular}

completed the decontamination work (excluding difficult-to-return zones).

Municipalities that have completed the decontamination work are, as mentioned earlier, conducting follow-up monitoring to ensure that the reduced dose levels are maintained. Furthermore, they continue to discuss necessary follow-up measures while maintaining close communication with local residents.

\section{Intensive Contamination Survey Areas}

While the Japanese government conducts decontamination work directly in special decontamination areas, municipal governments are leading the decontamination work in municipalities classified as intensive contamination survey areas in accordance with duly developed plans. As of July 2016, decontamination work had been conducted in 36 municipalities in Fukushima Prefecture.

According to their plans, the target municipalities in Fukushima Prefecture intend to complete decontamination work and other cleanup measures in FY2016. As of July 2016, nearly $90 \%$ of the decontamination work had already been conducted in residential areas, farmland, pastureland, living environments for children, and other public facilities. The decontamination work was completed for about $50 \%$ of roads and $60 \%$ of forests in habitation zones.

\section{Treatment of Contaminated Waste}

\section{Direct Treatment of Contaminated Waste by the Japanese Government}

Areas for the direct treatment of contaminated waste by the Japanese government were designated in 11 municipalities with an overlapping designation as special decontamination areas. As of January 2016, an estimated total of 1.165 million tons of disaster waste had been produced in these areas. By August 2016, 990,000 tons of waste from the affected sites had been consolidated in temporary storage yards, of which 150,000 tons had been treated by incineration and 380,000 tons had been recycled.

As part of ongoing efforts for evacuees to return to these areas, the clearance waste that they produce during their temporary return is also being collected and treated. In parallel, affected houses are also being demolished. As of August 2016, 3,900 houses had been demolished and removed in response to about 9,400 applications.

Plans were formulated for the construction of temporary incinerators to treat the combustible part of the disaster waste from these areas at nine sites in eight municipalities: Kawauchi, Iitate (Komiya District and Warabidaira District), Tomioka, Minamisoma, Katsurao, Namie, Naraha, and Okuma. As of October 2016, an incinerator was under construction in Okuma, 
an incinerator in Kawamura had completed the treatment work, and the remaining seven facilities in six municipalities were in operation with a total daily capacity of 1,600 tons. By August 2016, they had treated about 330,000 tons of waste (including 190,000 tons of decontamination waste).

\section{Treatment of Designated Waste}

Beyond the areas for the direct treatment of contaminated waste by the Japanese government, waste with a radioactivity level in excess of $8,000 \mathrm{~Bq} / \mathrm{kg}$ is treated by the Japanese government as designated waste. As of June 2016, Fukushima Prefecture had generated a total of about 147,000 tons of designated waste, which consisted of 116,000 tons of incinerated ash, 10,000 tons of sewage sludge, and 4,000 tons of rice straw and other agricultural and forestry byproducts.

The volume of combustible waste is being reduced with respect to agricultural and forestry byproducts, sewage sludge, and the like by means of incineration and drying. So far, facilities have been developed to reduce the volume of sewage sludge in Fukushima and Koriyama and to treat agricultural and forestry waste in Samegawa (all of these operations had been completed as of July 2016). The volume reduction facility in the Warabidaira District of Iitate treats combustible designated waste from the district and neighboring municipalities. The development of a volume reduction facility is planned at the switching station in Minami-Iwaki between Kawauchi and Tamura to treat agricultural and forestry byproducts from the Aizu region as well as the central and southern parts of the prefecture.

\section{Controlled Landfill Site}

Designated waste from Fukushima Prefecture with a radioactivity level of no more than $100,000 \mathrm{~Bq} / \mathrm{kg}$ will be disposed of at the existing controlled landfill site (formerly the Fukushima Eco-tech Clean Center) in Tomioka (transported through Naraha).

In December 2015, the town mayors of Tomioka and Naraha, along with the prefectural governor of Fukushima, endorsed the use of this facility, and the Japanese government nationalized the facility in April 2016. In June of that year, these bodies signed an agreement on safety measures to be implemented around the facility.

At the site, landfill disposal is planned for around $650,000 \mathrm{~m}^{3}$ of waste with a radioactivity level of no more than $100,000 \mathrm{~Bq} / \mathrm{kg}$ from among the waste produced in the areas for the direct treatment of contaminated waste by the Japanese government, designated waste, and household waste from Futaba. As of September 2016, the development of related facilities had begun and local coordination for waste transportation was underway.

\section{Construction of Interim Storage Facilities}

The construction of interim storage facilities with a combined area of roughly $16 \mathrm{~km}^{2}$ is planned in Okuma and Futaba. These facilities will store soil removed during decontamination work in Fukushima Prefecture, waste from areas to be treated directly by the Japanese government with a radioactivity level of over $100,000 \mathrm{~Bq} / \mathrm{kg}$, and designated waste. The amount of waste to be disposed of is estimated to be between 16 and 22 million $\mathrm{m}^{3}$ (after the incineration of combustible waste). 


\section{Land Acquisition}

In the summer of 2011, the Japanese government requested that the prefectural government of Fukushima collaborate in the construction of interim storage facilities. Since then, various exchanges have been conducted through on-site surveys, local briefing sessions, and other activities that involve evacuees and the national, prefectural, and relevant municipal governments. As a result, the town of Okuma agreed in December 2014 to host one of these facilities. The town of Futaba followed suit in January 2015. Subsequently, negotiations were entered into with the over 2,300 landowners of the intended sites. Searches were conducted to find out the contact details for evacuated landowners in all parts of Japan. The purpose of the interim storage facilities was explained to these landowners through meetings or phone calls to obtain the necessary consent with regard to their houses and other properties as well as for the performance of surveys there. The properties were appraised by examining the stumpage, garden rocks, houses, and other facilities one by one to estimate their values. After that, the respective landowners were contacted to proceed with a land acquisition agreement after the results of the appraisals had been confirmed. As of September 2016, the contact details of about 1,600 landowners had been confirmed. These landowners own about $90 \%$ of the planned site. After their contact details had been identified, 1,400 landowners agreed to the performance of a property survey. These landowners account for about $80 \%$ of the planned site. The property survey was completed for $60 \%$ of the planned site. Some properties require extra time for reconfirmation after the property appraisals based on on-site surveys. As of September 2016, land acquisition agreements had been signed for 144 ha of land.

\section{Transportation}

In February and March 2015, the towns of Okuma and Futaba agreed to accept contaminated soil at their interim storage facilities, respectively. In March 2015, the transportation of waste was commenced to the planned sites for interim storage facilities. Prior to the construction of the main facilities, parts of the industrial complexes in both towns were designated as storage spaces. In FY2015, the transportation of waste from 43 municipalities in Fukushima Prefecture was conducted as a pilot demonstration to determine the state of transportation safety management and the challenges associated with transportation to and from the facilities. In total, about $45,000 \mathrm{~m}^{3}$ of waste was transported to and from these facilities. The amount of waste to be transported is mostly determined by how much land is acquired at the planned sites by the previous year. According to the forecast, around $150,000 \mathrm{~m}^{3}$ will be transported in FY2016 before increasing to between 300,000 and 500,000, 900,000 and 1.8 million, and then 1.6 and 4.0 million in the following FYs. In FY2020, this number is expected to rise to between 2 and 6 million $\mathrm{m}^{3}$.

\section{Facility Construction}

Full-fledged construction of loading and segregation facilities, soil storage facilities, and other relevant interim storage facilities began in the autumn of 2016 when a substantial area was secured at the planned construction sites. At the planned interim storage sites, several sections of valleys that are separated by ranges of hills and covered with paddies extend toward the ocean. Initially, plans were formulated for facilities for the storage of vast amounts of soil to fill these valleys by forming something like dams. However, the land use and facility design must be flexibly adjusted to the status of land acquisition. 


\section{Recycling and Final Disposal}

Interim storage facilities are intended for the storage and management of soil generated during the performance of decontamination work in Fukushima Prefecture in the immediate future. The Act on Japan Environmental Safety Corporation stipulates the principles for the final disposal of this soil outside of Fukushima Prefecture within 30 years of it first being stored in these facilities. Progress toward the final disposal of this soil is envisaged to comprise eight steps. More specifically, research and development into the relevant technologies as well as an exploration of the potential for volume reduction and recycling are to be conducted while keeping in mind the physical decay of radioactive materials. Recycling is pursued by segregating fine-grained soil — which tends to adsorb more radioactive materialsfrom large-grained soil brought into the interim storage facilities after the completion of decontamination operations. The possibility of making effective use of soil with a relatively low dose is also investigated for the development of properly managed public facilities.

\section{Future Challenges}

\section{Handling of Forests}

Decontamination is usually conducted in forests that are located within about $20 \mathrm{~m}$ of residential areas, farmland, and the like while taking into consideration the impact on these areas. Reportedly, a subsistence economy has developed, particularly in the Abukuma Mountains, with a heavy reliance on forestry and the collection of edible wild plants, mushrooms, and other forest resources in other parts of Fukushima Prefecture with scattered radioactive materials. In response to calls voiced throughout the prefecture for careful attention to be paid to forests, a national agency began discussions in the beginning of 2016 on how forests should be handled. As an empirical experiment, a pilot demonstration for the restoration of community forests is planned.

\section{Measures in Difficult-to-Return Zones}

In special decontamination areas, decontamination work to date has been conducted in restricted residence zones and evacuation order cancellation preparation zones. Extensive decontamination work has not been conducted in difficult-to-return zones, except for at some pilot demonstration sites, the Joban Expressway, National Route 6, other expressways, cemeteries (which act as an important spiritual mooring for residents), and key reconstruction hubs in Okuma, Futaba, and Tomioka. In August 2016, the recommendations made by the ruling party with respect to measures to be taken in these zones were compiled. Accordingly, the government established a relevant policy at the end of that month.

The municipalities to be targeted in the future need to develop plans for the establishment of reconstruction hubs as well as conduct decontamination work and infrastructure development for these hubs. In addition, key roads will need to be cleaned up and improved to form an extensive network. 


\section{Communication of the Risks Involved in Decontamination Work and Other Measures}

The performance of decontamination work, the construction of interim storage facilities, the treatment of contaminated waste, and other such measures can be conducted thanks to the understanding and cooperation of affected residents and relevant agencies. In January 2012, the Japanese government established the Decontamination Information Plaza as a leading hub for risk communication in Fukushima City. In May 2014, the Support Center for Social Workers Engaged in Recovery from the Nuclear Disaster was opened in Iwaki City to facilitate radiation risk communication. Sometime later in July 2016, the prefectural government of Fukushima, the National Institute for Environmental Studies, and the Japan Atomic Energy Agency jointly opened the Fukushima Prefectural centre for Environmental Creation in Miharu to study environmental dynamics in the prefecture and engage in risk communication in a comprehensive manner.

Cooperation among these three facilities is vital, and their staff are now trying to coordinate and share information among themselves. They are expected to adequately respond to requests from Fukushima residents and provide them with the necessary advice.

Of these three facilities, the Decontamination Information Plaza has served as a platform for risk communication and exchanges in Fukushima since the early stages. Their activities can be outlined as follows.

- Purpose of establishment: Provision of information regarding decontamination work, radiation, etc.

- Management: Joint operation by the MOE and the prefectural government of Fukushima

- Activities

- Dispatching of experts: Registered experts on decontamination work and radiation are dispatched to workshops as requested by the municipalities

- Stationary exhibitions: Exhibitions and briefings are provided to facilitate greater understanding of decontamination work

- Mobile exhibitions: Exhibitions and briefings on matters related to radiation and decontamination work are provided at events as requested by the hosting municipalities

- Achievements (February 2012 to August 2016)

- 1,193 experts dispatched for over 47,000 participants at workshops

- Mobile exhibitions organized at 460 venues, with over 51,000 visitors being hosted over a total period of 593 days

- Over 22,000 people visit the Decontamination Information Plaza

\section{Conclusions}

With respect to the issue mentioned at the beginning of this report, although some children from Fukushima may be resilient enough to adequately explain the local conditions and talk about radiation, some children might be discouraged from eating local rice and drinking local water. It seems odd for host communities to ask children who have had to move away from their home prefectures to explain about Fukushima. Instead, the host communities should learn more about decontamination work and radiation so that they can offer vital support to these young new members of the community.

In Japan today, this approach is probably one way for the country to genuinely apply the 


\section{INSIGHTS CONCERNING THE FUKUSHIMA DAIICHI NUCLEAR ACCIDENT Vol. 2}

lessons learned from Fukushima.

\section{General References}

1) Seiji Ozawa: Progress on Off-site Cleanup Efforts in Fukushima, Journal of the Atomic Energy Society of Japan, Vol. 57, No. 6, pp. 25-28 (2015).

2) Measures against radioactive materials: http://www.env.go.jp/jishin/rmp.html.

3) Website on decontamination: http://josen.env.go.jp.

4) Website on a pilot decontamination demonstration by the JAEA.

5) Website on changes in air dose rates after a pilot decontamination demonstration. 